\title{
Santa Clara de Allariz, historia dunha fundación real (ss. XIII-XV)
}

\author{
Ma Batriz Vaquero Díaz \\ Universidade de Vigo
}

DOI: 10.17075/gtax.2021.007 



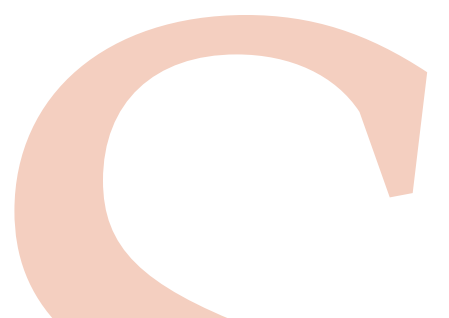

O presente traballo pretende facer un breve retrato do mosteiro de Santa Clara de Allariz ao longo da Idade Media, baseado nunha colección documental que inclúe 376 documentos, dos que dous pertencen ao século XII, noventa ao XIII, cento catro ao XIV e cento oitenta ao xv; documentación custodiada na súa maior parte nos arquivos Histórico Provincial de Ourense e Histórico Nacional e, en moito menor medida, nos do propio mosteiro de Santa Clara, da Catedral de Ourense e do reino de Galicia ${ }^{1}$ O número e a tipoloxía dos documentos conservados revelan a importancia da perda documental que sufriu o convento, que deixa moi pouca información sobre a organización interna da congregación e a vida en comunidade, e orienta forzosamente o estudo cara aos vínculos institucionais co Papado e a Coroa a través dos privilexios pontificios e reais, ao rol que os lazos familiares e devocionais da nobreza xogaron na formación do patrimonio monástico a través de testamentos e doazóns, aos conflitos pola salvagarda dese patrimonio a través dos preitos nos que o convento litigou con señores, oficiais reais e concellos, e, por último, á adquisición e explotación das terras de cultivo a través de contratos de compravenda e aforamento.

O estudo preséntase dividido en catro apartados adicados o primeiro ao estudo da fundación, o segundo ao dominio monástico, o terceiro ás rendas reais e actividades gandeiras e agrícolas, e o cuarto á composición social, organización interna e vida da comunidade.

\section{A FUNDACIÓN}

A primeira noticia do mosteiro de Santa Clara de Allariz data do ano 1282, cando Mateo, cardeal de Santa María in Porticu, sabedor de que a raíña Violante de Aragón decidira fundar un mosteiro de monxas clarisas en Allariz, ordena aos responsables dos Frades Menores da provincia de Santiago e ao custodio, gardián e lec-

1 A edición da colección documental de Santa Clara de Allariz nace do entusiasmo de Mercedes Durany polo estudo da historia de Allariz e nela participamos a propia Mercedes, Francisco Javier Pérez Rodríguez, Mํa Ascensión Enjo Babío, Ma José Losada Meléndez, Amalia López Martínez, Víctor Rodríguez Muñiz e eu mesma, integrantes do grupo de investigación de Historia Medieval da Universidade de Vigo, que me permitiron utilizar o seu traballo antes da súa publicación na colección Gallaecia Monumenta Historica do Consello da Cultura Galega. 
tor do convento franciscano de Ourense, que vixíen e contribúan á súa constitución². Catro anos máis tarde, en 1286, Macías Nunes, procurador da abadesa e monxas de Santa Clara de Zamora, de onde procederán a primeira abadesa e monxas do convento allaricense, aparece en Allariz mercando herdades no Pombal para construír sobre elas o novo mosteiro e ese mesmo ano o rei Sancho IV, a petición da súa nai Violante de Aragón, ordena que se faga o convento de clarisas na vila e acouta o lugar en que será construído. Haberá que esperar a 1288, para que apareza na documentación a primeira abadesa, Sancha Eanes, e aínda máis, ata 1294, para que o bispo de Silves, frei Domingo, poña a primeira pedra da igrexa e a consagre xunto co cemiterio 3 .

En 1292, dous anos antes da consagración, dona Violante outorga un testamento no que promete tomar a orde de Santa Clara no mosteiro de Allariz e acabar a súa vida nel, elixe o coro das monxas na igrexa de Santa María como lugar de enterramento e revoga dúas promesas anteriores nas que sinalaba como lugares de enterramento o mosteiro no que fora soterrada a súa nai Violante de Hungría e o convento de Zamora do que ela mesma fora benfeitora. Como fundadora dota xenerosamente á congregación con 200000 marabedís dos da guerra: 100000 para a obra do mosteiro e 100000 para bens destinados ao mantemento das monxas. Deixa tamén 4000 marabedís para libros e a súa capela, outros 6000 para mercar bens cos que se manteña un capelán que cante misa diaria por ela e os seus familiares, e para o seu enterramento 10000 marabedís, o seu leito e toda a súa roupa ${ }^{4}$.

As motivacións do proceder de dona Violante parecen responder tanto a causas de tipo persoal como político. Dende o punto de vista persoal, a súa actuación en Allariz pon de manifesto o seu interese por ir máis aló do papel de benfeitora para converterse en fundadora dun convento, condición que, sen menoscabo da súa devoción, lle permitiría concentrar nel os seus ingresos e obter unha residencia ocasional na que refuxiarse, xa viúva, lonxe da problemática situación familiar que provocou o enfrontamento dos infantes De la Cerda co futuro rei Sancho IV (Katz 2015: 813 e 826). Todo parece indicar que dende o punto de vista económico a fundación cumpriu as súas expectativas pero non sucedeu o mesmo co proxecto de vida en comunidade posto que non existe ningunha proba de que a raíña vivise nin fose soterrada en Allariz, situación que ela mesma predixo no seu testamento cando afirma que o outorgaba por se «non pudiese tomar la orden asi como sobredicho es» ${ }^{5}$.

2 AHN, Clero, Santa Clara de Allariz, 1429/1.

3 AHPOu, Santa Clara de Allariz, C. 6/13 e C. 6/14; AHN, Clero, Santa Clara de Allariz, 1430/8; AHPOu, Santa Clara de Allariz, Lib. 66/54v; AHN, Clero, Santa Clara de Allariz, 1429/10. Durany pon en dúbida a procedencia zamorana da abadesa Sancha Eanes argumentando unha posible filiación con Gonzalo Eanes de Zarracós (Durany 2009: 136).

4 AHN, Clero, Santa Clara de Allariz, 1429/5. Doazóns confirmadas por dona Violante en 1295, nun documento que inclúe tanto o outorgado no primeiro documento como todo canto puidese doar en diante (AHPOu, Santa Clara de Allariz, C. 6/25).

5 AHN, Clero, Santa Clara de Allariz, 1429/5. García Oro afirma taxativamente que a raíña nin viviu nin foi enterrada en Allariz (García Oro 1999: 144) e tampouco Katz pode demostrar que o seu corpo fose trasladado a Galicia dende Roncesvalles, lugar onde faleceu (Katz 2015: 827-829). 
Segundo García Oro, Violante de Aragón foi a precursora do padroádego real das ordes mendicantes que, entre o último cuarto do século XIII e a primeira metade do XIV, sería utilizado pola Coroa para converter Santa Clara de Allariz na clave de bóveda dun proxecto concibido para «equipar no lonxano reino galego unha cidade rexia» consolidada coa fundación do mosteiro e convertida no centro dun infantado en Galicia; proxecto que, de ter existido, non chegou nunca a plasmarse na realidade (García Oro 1999: 116 e 132-133). Máis realista parece a tese proposta por Pérez Rodríguez, segundo a cal foron a relevancia da condición de vila de reguengo de Allariz e o contrapeso que supuña a fundación fronte ao señorío episcopal de Ourense as razóns da escolla da vila como localización das clarisas (Pérez 2018: 102).

Pese ao decidido apoio real e pontificio á fundación de Santa Clara, a súa consagración resultou accidentada ao verse afectada polo conflito xurdido nos últimos anos do século XIII entre Pedro Eanes de Nóvoa, bispo de Ourense, e os franciscanos da cidade (Pérez 2018: 109-110). A negativa do bispo de Ourense de consagrar a igrexa e o cemiterio motivou que o bispo de Silves, frei Domingo, acudise a Allariz en 1294 para poñer a primeira pedra da igrexa e consagrala xunto co cemiterio, despois de que a abadesa Sancha Eanes llo pedise argumentando que «porque assi, como vós sauedes, a eigleia non se pode fazer como deue si algun bispo y non poer a primeira pedra e non consagrar o çimiterio» ${ }^{6}$.

Fronte aos problemas eclesiásticos que dificultaron o inicio da vida canónica de Santa Clara, o mosteiro foi apoiado sen fisuras por Violante de Aragón, o seu fillo Sancho IV e os monarcas que o sucederon, co outorgamento de abundantes concesións e confirmacións de privilexios (García Oro 1999: 140-143 e Nieto 1990: 122).

A fundación real e a elección que en 1327 o infante don Filipe e a súa muller dona Margarida fixeron da igrexa conventual como lugar de sepultura outorgaron a Santa Clara un prestixio que converteu ao mosteiro no lugar de enterramento de destacados personaxes da nobreza ourensá baixomedieval. Enterramentos acompañados coa fundación de capelas, nas que se oficiarán misas cantadas polas almas dos oferentes, e que serán financiados con espléndidas mandas testamentarias ${ }^{7}$.

De todo o patrimonio arquitectónico e escultórico que deberon xerar os enterramentos (sepulturas, covas, monumentos) e capelas nas que se cantarían misas pola alma do defunto, non quedan na actualidade máis probas materiais que algúns arcos góticos reciclados como peches de vans posteriores ou utilizados para sepulcros na coxía norte do claustro baixo, polo que a única información coa que contamos é a que proporcionan os testamentos e doazóns nos que se ordena a súa cons-

6 AHN, Clero, Santa Clara de Allariz, C. 4900, 1-1-1/7rv e De los Ríos 1973: 931-932.

7 A libertade de sepultura para quen queira ser enterrado no mosteiro de Santa Clara foi concedida por Nicolás IV en 1291 (Domínguez 2009: 441, n. 478). Para o documento de Afonso XI, AHN, Clero, Santa Clara de Allariz, 1430/3. 
trución e mantemento ou os documentos de época moderna nos que se describe o estado das edificacións ${ }^{8}$.

Paradigmático é o caso de Rodrigo Páez de Biedma, copeiro maior do infante don Pedro, que no seu testamento redactado en 1342 pide que o «enterrem dentro, eno moesteyro de Santa Clara d'Allariz, aos pẽes da sepultura en que jaz o inffante don Fillipe; et se acaesçer de tiraren o corpo do inffante dom Fillipe dalli onde agora iaz, mando que en aquelle lugar en que o a el trasladaren que y me deyten, á par da sepultura do dito inffante, en hũa sepultura que seia mays bayxa que a de dom Fillipe»?.

Paradigmático pero non único posto que entre 1302 e 1402 se conservan outros catro testamentos nos que os outorgantes, Gonzalo Eanes de Zarracós e a súa viúva María Vázquez, Tareixa Pérez Feixoo e dona Aldonza, aia da raíña de Castela, mandan que os enterren no mosteiro e fundan senllas capelas ${ }^{10}$.

\section{O DOMINIO}

A formación do dominio de Santa Clara comezou coa concesión, feita por Sancho IV entre 1286 e 1293, de cinco privilexios nos que define, outorga e acouta o espazo no que se construirá o mosteiro; autoriza ás monxas para que poidan dispoñer dos seus bens e entregar ao mosteiro, se así o desexan, o obtido coa súa venda, establecendo como única limitación que este alcance un patrimonio de 40000 marabedís da guerra; e asenta os privilexios e exencións de que gozará o couto"11.

Definido como «aquel lugar do ellas an de fazer el monesterio, por aquellos terminos que Iohan Rodriguez, nuestro alcallde, gelo amojone por nuestro mandado», o couto debeu resultar un espazo moi limitado; de feito, o 12 de xullo de 1293 o rei aumenta a súa extensión autorizando que se faga unha poboación xunto aos edificios conventuais para que nela se establezan «los menestrales de qualesquier menesteres que seam para las obras del monesterio, et sus omes e sus apaniaguados». Os poboadores, presentes e futuros, serán vasalos do convento e recibirán o seu foral, quedando así mesmo exentos de todo tributo rexio salvo o de moeda foreira. E, por último, concede nese mesmo ano dous novos documentos: no primeiro exime ao

8 García González 1990: 232. García Barriuso publica o informe escrito en 1613 polo deán Gerónimo Chirinaga sobre o convento no que afirma que no coro só se permite a sepultura dos corpos reais (dona Violante, o infante don Filipe e dona Margarida) mentres que no corpo da igrexa, ao carón da pía de auga bendita, están soterrados Xoán Rodríguez de Biedma e frei García Blanes (García Barriuso 1990: 84-85)

9 AHN, Clero, Santa Clara de Allariz, 1429/20.

10 AHPOu, Santa Clara de Allariz, C. 6/29. ACO, Monacais, 1765. AHPOu, Santa Clara de Allariz, C. 6/44. AHPOu, Santa Clara de Allariz, 9788, C. 51/1r-2v. Existe un cuarto testamento destas características expedido en 1299 pero a súa deterioración non permite ler o nome da testadora (Arquivo do convento de Santa Clara de Allariz, n.․ㅜ 18).

11 AHN, Clero, Santa Clara de Allariz, C. 1430/8. AHN, Clero, Santa Clara de Allariz, C. 1429/4 e 8. 
convento de permitir a entrada dos oficiais reais para tomar prendas ou facer xustiza, e no segundo estende a exención do pago de todo tributo rexio salvo moeda foreira aos lugares e herdades do mosteiro e aos homes que vivan neles ${ }^{12}$.

Tan importante como o apoio de Sancho IV e dos reis que confirmaron os seus privilexios foi a concesión de dúas bulas: a outorgada por Gregorio XI en 1375 acollendo baixo protección apostólica ao convento de Santa Clara de Allariz e aos seus bens, e a Laudabilis sacra religio de Bonifacio VIII, de 1296, que exime aos conventos da Orde de Santa Clara do pago de todo imposto laico ou eclesiástico, exención que na década dos setenta do s. XIV confirma o bispo auriense don Martiño ao outorgar ás monxas que non sexan obrigadas a pagar nas súas posesión presentes ou futuras o décimo nin outros impostos eclesiásticos nin «quaesquer tallas e colleitas, nen a pagar portagen nen dereyturas nen outras exações et posturas a quaesquer reys e prinçipes ou outras pesõas seglares» ${ }^{13}$.

Na documentación medieval de Santa Clara unicamente en tres ocasións aparecen incumprimentos sobre a exención de peitas ás persoas que vivisen nas casas do convento e traballasen as súas herdades que obrigaron ao mosteiro a reclamar ante os xuíces de Allariz para que se respectase o mandato de Sancho IV. Na primeira, segundo consta nunha sentenza de 1378, foi o concello da vila o que a incumpriu cando «lles lleuauan e querian lleuar los dichos pechos e trebutos cada que en la dicha villa de Allariz eran demandados», razón pola cal a abadesa afirmaba que non podía «auer pobladores ningunos pera las casas del dicho monesterio, nin otrosi lauradores pera las herdades que al dicho monesterio pertenesçian». O xuíz sentencia a favor do convento pese a que o concello de Allariz argumentaba que a súa conduta era debida a que algúns veciños da vila ían residir nas casas do mosteiro, malia non ser caseiros del nin labrar as súas herdades, para non pagar as peitas e tributos co concello ${ }^{14}$. Nas outras dúas reclamacións, realizadas polo mosteiro en 1420 e 1427, o convento denuncia ante os xuíces de Allariz que os cobradores do portádego da vila non gardan os privilexios e exencións de que gozan o convento e os seus dependentes. Reclamacións nas que os xuíces volven dar a razón ao mosteiro, e ordenan aos portageyros da vila que cesen no cobro do portádego e devolvan as cantidades confiscadas como garantía do pago aos familiares e caseyros do mosteiro ${ }^{15}$.

Sobre o concello do couto apenas existen mencións nos séculos medievais, quizais porque as súas pequenas dimensións e a importancia da vila e concello de Allariz anulou ou reduciu drasticamente a súa actividade de forma semellante á que Olga Gallego describe para o ano 1560, cando se produce a súa desmembración (Gallego 1986b: 142). A documentación medieval menciona unicamente tres xuíces:

12 AHN, Clero, Santa Clara de Allariz, C. 1429/8. AHN, Clero, Santa Clara de Allariz, C. 1430/8.

13 Ed. A. López 1915: 46-47. J. H. Sbaralea (1768): 401. Tradución da confirmación da bula de Bonifacio VIII en AHN, Clero, Santa Clara de Allariz, C. 1430/10.

14 AHN, Clero, Santa Clara de Allariz, C. 1430/5.

15 AHPOu, Santa Clara de Allariz, Lib. 47/157r e 156r. 
Xoán Fernández, veciño e morador do couto, aparece en 1473 como mordomo e procurador do mosteiro e xuíz do couto de Santa Clara; Vasco de Nanín, morador en Nanín, vasalo e caseiro do mosteiro, aparece como xuíz do couto en 1487, e Pedro Alfaiate figura en 1496 como morador no couto e xuíz, procurador e mordomo da abadesa de Santa Clara dona María Méndez de Zarracós ${ }^{16}$.

No documento de desmembración do couto outorgado por Filipe II cítanse cinco granxas «anexas ao couto» habitadas por vasalos do mosteiro e situadas en Roiriz, A Torre, Lamas, Nanín e Figueiredo (Gallego 1986b: 139-141 e Sánchez/Enjo 2011-2012: 774 e 778). Posiblemente a extensión do foral do couto a «todos os otros sus lugares, poblados e por poblar, que agora an o averan d'aqui adelante en todos nuestros regnos» e a prohibición da entrada nel aos adiantados, meiriños e oficiais reais, que outorgaría de facto a eses lugares o dereito de poñer neles xuíces e nomear os seus propios oficiais, fosen a causa do nacemento das granxas en núcleos territoriais situados nas inmediacións de Allariz, nas que se concentraba un número relevante de propiedades monásticas habitadas por vasalos do mosteiro ${ }^{17}$.

A única mención conxunta destes cinco lugares na documentación medieval de Santa Clara prodúcese no ano 1489 nunha sentenza de Sancho García del Espinar, alcalde maior do reino de Galicia, contra o concello de Allariz por non respectar as exencións concedidas aos vasalos do couto do convento por Sancho IV e confirmadas polos seus sucesores. Nela os únicos vasalos e caseiros do mosteiro prendados por non participar nun pedido de Xoán Pimentel, señor de Allariz, aos que se prohibe levar o seu gando a pastar nos prados do concello, reciben os nomes de Vasco de Nanin, Rodrigo de la Torre, Alonso de Laja, Gonçalo de Ruyriz e Pero de Figueiredo. Antropónimos que coinciden cos nomes das granxas anexas, salvo no caso de Laja, posible erro do notario que expide o documento. A única información sobre a incorporación a Santa Clara deses lugares é a que aparece nunha doazón de dona Aldonza Nunes en 1289 e nun foro outorgado polo marchante Pedro Gómez en 1485 que revela que, a finais da Idade Media, Santa Clara seguía posuíndo unicamente unha parte das herdades do lugar de Nanín ${ }^{18}$.

Ademais do couto do propio mosteiro nas aforas da vila de Allariz, Santa Clara posúe tamén os coutos de Mourazos, Loureses, Nocelo da Pena e Mañoi ${ }^{19}$.

O couto de Loureses foi doado a Santa Clara no testamento de Xoán Rodríguez de Biedma no ano 1400 «con todas las rendas que eu y ey, e labranças de pan, e seruiçios, e senorio, e outras casquer coussas que me a min y perteesçe de aber en qualquier manera» e cinco anos despois a súa víuva Tareixa López de Orozco, reco-

16 AHPOu, Santa Clara de Allariz, Lib. 10/101r. AHPOu, Santa Clara de Allariz, Lib. 5/24rv. AHPOu, Santa Clara de Allariz, Lib. 14/232r-234r.

17 AHN, Clero, Santa Clara de Allariz, C. 1430, n.ํ 8. Ed. A. López (1927): 27. P. García Barriuso (2002): 31 .

18 AHPOu, Santa Clara de Allariz, Lib. 47/405r. AHPOu, Santa Clara de Allariz, Lib. 6/8r.

19 O couto de Mourazos está situado no actual concello de Verín, Loureses no dos Blancos, Nocelo da Pena en Sarreaus. 
ñece ao mosteiro o dereito á posesión do couto e desembarga as súas rendas e bens. E en 1482 o conde de Monterrei, Sancho de Ulloa, doa ao mosteiro para que recen pola alma da súa muller, Tareixa de Estúniga, unha vaca que o concello de Loureses lle daba anualmente ${ }^{20}$.

O couto de Nocelo da Pena foi tamén entregado ás monxas por Xoán Rodríguez de Biedma no seu testamento, co mesmo tipo de bens e por idénticas razóns piadosas ás alegadas para a doazón de Loureses. A seguinte información sobre o couto procede da pescuda e apeo que realiza en 1496 o seu xuíz Pedro de Pazos ${ }^{21}$.

Pola súa parte, a incorporación do couto de Mourazos ao patrimonio de Santa Clara realizouse mediante o outorgamento de dúas doazóns. Na primeira, Xoán Rodríguez de Biedma e Tareixa López de Orozco outorgan, en 1394, os bens que tiñan na aldea de Mourazos para que o mosteiro faga nela unha granxa, e na segunda, en 1482, Sancho de Ulloa entrega ao mosteiro os tres casais que posúe no lugar, o que converte a Mourazos en couto redondo ${ }^{22}$.

E, por último, o mosteiro de Santa Clara posúe o couto de Mañoi, lugar situado na contorna do río Arnoia, que non é posible localizar na actualidade. Sabemos da súa existencia por un documento do ano 1376 no que Clara Afonso, monxa Santa Clara, afora, entre outros moitos casares e herdades, o seu couto de Mañoi e sinala ao mosteiro como a súa voz a perpetuidade despois da súa morte ${ }^{23}$.

En boa lóxica os catro coutos que posúen as clarisas debían ter un concello, por reducido que fose; porén para os séculos medievais só existen dúas mencións. Na primeira, de 1482, aparece en Loureses un conçejo que, xunto cos omes buenos de Loreses, son responsables da entrega anual dunha vaca o día de Todos os Santos ao conde de Monterrei, renda que este doará ao mosteiro de Santa Clara. En Mourazos haberá que esperar ao ano 1491 para ter a primeira noticia do seu concello, con motivo da usurpación da xurisdición do couto que pretendeu facer Francisco de Estúniga ${ }^{24}$.

Fóra dos coutos, a documentación sitúa as terras de cultivo do convento nos arredores do actual termo municipal de Allariz, situados nos concellos de Rairiz de Veiga, A Bola, Cartelle, A Merca, Taboadela e Paderne de Allariz. Esa disposición parece responder á existencia das granxas da Torre, Nanín, Roiriz e Figueiredo, que concentrarían a maior parte das herdades nas inmediacións da vila.

A maioría desas propiedades adícanse ao cultivo do cereal, e as poucas mencións referidas ao cultivo da vide sitúan as viñas preto de Allariz, nas parroquias de Pazos de San Clodio e Proente e no lugar de Santa Locaia, que conta ademais

20 AHPOu, Santa Clara de Allariz, Ca. 9781/15, 7v-9r. AHPOu, Santa Clara de Allariz, Ca. 9781/15, 7r-9v. AHPOu, Santa Clara de Allariz, Lib. 31/8-9.

21 AHPOu, Santa Clara de Allariz, Ca. 9781/15, 7v-9r. AHPOu, Santa Clara de Allariz, Lib. 14, 232r-234r.

22 AHN, Clero, Santa Clara de Allariz, C. 1430/6 e AHPOu, Santa Clara de Allariz, Lib. 31/8-9.

23 AHPOu, Santa Clara de Allariz, C. 6/46.

24 AHPOu, Santa Clara de Allariz, Lib. 31/8-9 e 17rv. 
cun lagar. Menos numerosas aínda son as viñas situadas nas inmediacións da vila de Monterrei e nas parroquias de Pazos e Tamaguelos, no actual concello de Verín.

\section{RENDAS REAIS, GANDARÍA E AGRICULTURA}

Fundamentais na composición do patrimonio monástico foron as rendas reais outorgadas ao mosteiro de Santa Clara. Concedeunas Afonso XI que en 1329, obedecendo o desexo dos xa defuntos infante don Filipe e dona Margarida, doa ao convento de Santa Clara de Allariz, «para el mantenimiento de su monasterio», catro mil marabedís anuais situados, dous mil deles, nas rendas e dereitos reais en Castrelo de Miño, e os outros dous mil sobre os dereitos reais en Viana e no Bolo, e sinala como responsables directos do cobro os recadadores das rendas (pechos) e dereitos nos ditos lugares, con independencia do tipo de contrato - en renta, o en fialdat, o en otra manera qualquier - que os capacite para exercer ese labor ${ }^{25}$.

Nas décadas que seguiron á concesión foron constantes os incumprimentos na entrega das rendas e as consecuentes protestas e demandas que o mosteiro de Santa Clara se viu forzado a realizar. Na primeira delas, sobre as rendas de Viana e do Bolo, de 1336, o mosteiro denuncia ante Afonso XI a Pedro Fernández de Castro e os tenentes dos castelos de Viana e O Bolo porque lles embargan os 2000 marabedís anuais que el mesmo lles concedera en 1329. O rei afirma estar obrigado a adicar esa renda á intendencia dos castelos e compensa ao mosteiro outorgándolle 2000 marabedís nos décimos do porto de Bayona de Miñor, ao tempo que confirma os outros 2000 situados sobre as rendas e dereitos de Castrelo de Miño, e engade 2000 máis concedidos como un xuro de herdade que debe pagar anualmente a cámara real ${ }^{26}$.

O segundo grupo de demandas xira arredor dos 2000 marabedís situados sobre as rendas e dereitos de Castrelo de Miño e foron presentadas entre 1417 e 1433 ante os xuíces do couto de Castrelo de Miño, do rei en Ribadavia, de don Diego de Estúniga, e do mordomo deste último, Xoán Soutelo, e nas sentenzas de todas elas aparecen os recadadores das rendas como responsables dos impagos ${ }^{27}$. Será en 1432, cando as demandas do mosteiro chegan aos correxedores do rei en Galicia, que se comece a sinalar ao concello e habitantes do couto de Castrelo de Miño como culpables do incumprimento, e os sentencien a cumprir coas obrigas para co mosteiro de Santa Clara e ao pago das custas do xuízo. O mesmo sucede coa sentenza do ano

25 AHN, Clero, Santa Clara de Allariz, C. 1430/3.

26 AHN, Clero, Santa Clara de Allariz, C. 1430/3.

27 Para a comunicación da sentenza: AHPOu, Santa Clara de Allariz, Lib. 47/166r. Para a carta executoria da sentenza: AHPOu, Santa Clara de Allariz, Lib. 47/157r-159v; AHPOu, Santa Clara de Allariz, Lib. 47/165; AHN, Clero, Santa Clara de Allariz, Lib. 47/162; AHN, Clero, Santa Clara de Allariz, C. 1430/3. AHN, Clero, Santa Clara de Allariz, Lib. 47/163; 160r; 215v-217r. Para a doazón da renda do celeiro en Vilanova dos Infantes: AHN, Sigiliografía, Ca. 57/1. AHPOu, Santa Clara de Allariz, Lib. 47/215r-218v. 
1481, ditada polo gobernador do reino de Galicia, Fernando de Acuña, aínda que neste caso o documento evidencia a submisión do concello aos seus señores, os condes de Monterrei e Ribadavia, que reparten a medias o couto, cando «dize que la mytad que cabe a pagar a lo del conde de Monterrey se le paga, e que lo que cabe a pagar al conde de Ribadauia non gelo queria pagar» ${ }^{28}$.

En 1482 un acordo co concello da vila de Baiona revela que tamén a recadación dos 2000 marabedís dos décimos dos portos de Galicia que se realizaba en Baiona causou problemas ao mosteiro de Santa Clara, aínda que de menor envergadura e máis puntuais, segundo o que sabemos pola documentación conservada ${ }^{29}$.

Unha das actividades que se revela como importante durante a Idade Media para o mosteiro é a gandaría. Na documentación de Santa Clara aparecen nos séculos medievais porcos e porcallas formando parte das dereituras entregadas nos foros e con moita menos frecuencia vacas e bois, estes últimos formando parte de xugadas entregadas ao mosteiro en mandas ou doazóns que se utilizan para labrar as terras ${ }^{30}$.

A presenza do gando ovino entre os bens doados ao convento de Santa Clara de Allariz aparece por primeira vez no testamento de Violante de Aragón, cando cita entre os bens incluídos nas compras que fixo para o mosteiro «oueyas e vacas e otros ganados qualesquier» ${ }^{31}$. A cita, pouco relevante ao ser unha relación xenérica que pretende cubrir todas as posibles posesións, verase apoiada polo privilexio outorgado en 1302 por Fernando IV, no que concede ao mosteiro e aos seus pastores a exención total de impostos sobre 1500 cabezas de ovellas e carneiros, permite que os rabaños se movan e pasten libremente e que os pastores poidan cubrir as súas necesidades de leña e cortiza para o calzado nos seus montes. Concesión confirmada por Afonso XI en dúas ocasións: na primeira, de 1319, a petición do convento e coa intercesión do infante don Filipe, o rei aumenta o número de cabezas de gando exentas de impostos ata 2000, e na segunda, de 1326, confirmará ese segundo documento ${ }^{32}$.

É de supoñer que coas exencións concedidas pola Coroa ao mosteiro de Santa Clara de Allariz, este gozou dunha situación privilexiada na cría de gando ovino e na comercialización da la. Porén só aparece unha mención fóra da documentación real, referida ás cen ovellas no couto de Mourazos que Xoán Rodríguez de Biedma doa ao mosteiro do ano 1394, e, segundo Olga Gallego, non existe ningún dato

28 AHPOu, Santa Clara de Allariz, Lib. 47/165 e 162.

29 AHPOu, Santa Clara de Allariz, Libro 47/375.

30 «Hun jugo de boys, dessos meus que y andan, e duas vacas» no testamento de Fernando Eanes de Ourense, alcalde do rei en Monterrei, de 1310 (ACOu, Escrituras 2/41); «hun par de boys» no testamento de Pedro Eanes do Portelo en 1402 (AHPOu, Santa Clara de Allariz, C. 6/51); unha vaca que o concello de Loureses entrega cada ano a Sancho de Ulloa e que este dona a Santa Clara en 1482 (AHPOu, Santa Clara de Allariz, Lib. 31/8-9.); e o gando de Santa Clara ao que o concello de Allariz non permite pastar nos seus prados (AHPOu, Santa Clara de Allariz, Lib. 47/405r).

31 AHPOu, Santa Clara de Allariz, C. 6/25.

32 AHN, Clero, Santa Clara de Allariz, C. 1429/17. 


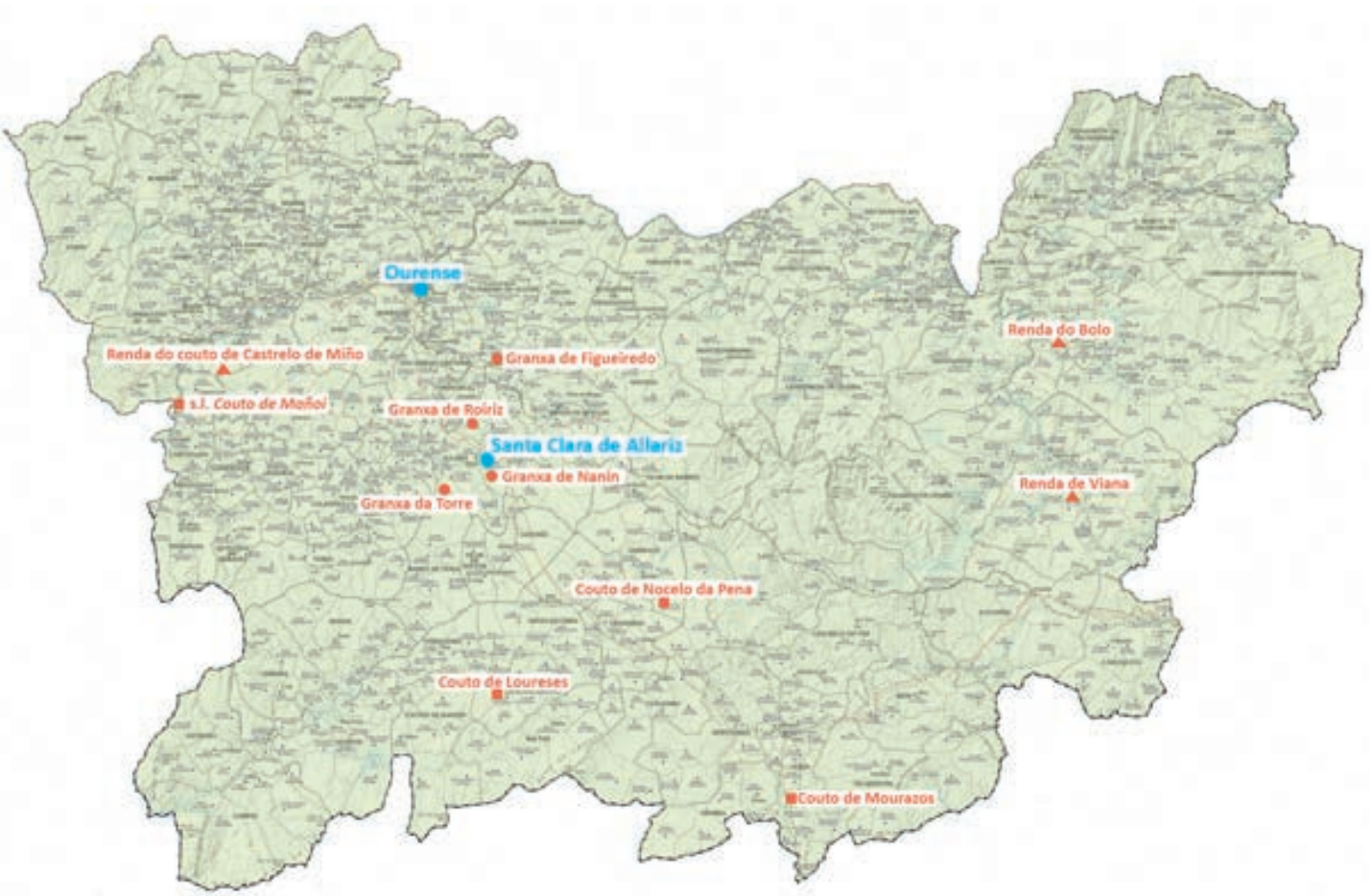

Mapa de coutos, granxas e rendas de Santa Clara de Allariz [Elaboración propia sobre o Mapa de parroquias de Galicia 1:200.000 (2009)].

concreto sobre a cría de gando ovino nin a comercialización da la na Idade Moderna (Rodríguez 1993: 225 e Gallego 1986a: 52-53)33.

Tampouco consta na documentación medieval que o mosteiro de Santa Clara tivese o dereito de presentación de ningunha igrexa, nin sequera sobre Santa María da Pinza, igrexa da diocese de Astorga e situada no actual concello de Viana do Bolo, que si aparece vinculada a el na Idade Moderna (Gallego 1986a: 56 e García Barriuso 1990: 86).

\section{A COMUNIDADE}

Durante a Idade Media, a comunidade do mosteiro de Santa Clara de Allariz estivo organizada xerarquicamente cunha abadesa á fronte da institución, as vigairas, auxiliares ou suplentes en caso de necesidade da abadesa na administración económica, e o convento integrado polas monxas. 
Entre os anos 1288 e 1500 documéntanse trece abadesas á fronte mosteiro. A primeira, Sancha Eanes, que lidera a construción e establecemento da casa no período da fundación entre os últimos anos do século xiII e principios do século XIV; sete no século XIV: Toda Díaz, Urraca Martiz ${ }^{34}$, María Fernández, Constanza López, Eusebia, Leonor e Leonor González, que exercerá o cargo tamén nos primeiros anos do século seguinte; e seis ao longo do século xv: Margarida Gómez, Moor de Limia, Moor de Silván, Leonor Álvarez de Robreda, Sancha Salgada e María Méndez de Zarracós, documentada ata o ano 1507 (vide Táboa 1).

\begin{tabular}{|c|c|c|}
\hline Datas & Nome & Outros cargos e filiación \\
\hline 1288-1309 & Sancha Eanes & \\
\hline $1312-1331$ & Toda Díaz & $\begin{array}{l}\text { Monxa de Santa Clara (1293) } \\
\text { Filla de Pedro Eanes Feixoo e dona Elvira } \\
\text { Irmá de Tareixa Pérez }\end{array}$ \\
\hline 1334 & Urraca Martiz & \\
\hline $1345-1347$ & María Fernández & $\begin{array}{l}\text { Monxa (1310) } \\
\text { Filla de don Fernando Eanes de Ourense: } 109\end{array}$ \\
\hline $1350-1364$ & $\begin{array}{l}\text { Constanza López } \\
\text { Vigaira Berenguela López (1361-1363) }\end{array}$ & \\
\hline 1364 & Eusebia [...] & Filla de Rodrigo González \\
\hline 1376-1379 & Leonor & \\
\hline $1394-1413$ & Leonor González & \\
\hline $1420-1444$ & Margarida Gómez & $\begin{array}{l}\text { Monxa (1404-1408) } \\
\text { Filla de Xoán González de Camba e Sancha } \\
\text { Nunes sobriña de Xoana e Sancha Nunes }\end{array}$ \\
\hline 1446 & Moor de Limia & Curmá de don Xoán de Estúniga \\
\hline 1450 & Moor de Silván & \\
\hline $1454-1480$ & $\begin{array}{l}\text { Leonor Álvarez de Robreda } \\
\text { Vigaira Beatriz Afonso (1454) }\end{array}$ & $\begin{array}{l}\text { Monxa (1429) } \\
\text { Abadesa vella (1481-1482) }\end{array}$ \\
\hline $1480-1493$ & Sancha Salgada & Monxa (1462-1480) \\
\hline $1495-1507$ & $\begin{array}{l}\text { María Méndez de Zarracós } \\
\text { Vigaira Tareixa García (1500) }\end{array}$ & Monxa (1462-1480) \\
\hline
\end{tabular}

Táboa 1. Abadesas e vigairas de Santa Clara de Allariz (séculos XIII-XV).

Entre as funcións das abadesas estaba o coidado espiritual e material das relixiosas, a administración dos bens do mosteiro e a elección dos cargos que debían auxilialas nesas tarefas (Rodríguez 1993: 99-101). Non obstante, debido á irregular conservación dos fondos documentais de Santa Clara, apenas temos noticias sobre as

34 Sen localizar, incluída por Rodríguez Núñez na listaxe de abadesas de Santa Clara (Rodríguez 1993: 297). 
funcións de «nai espiritual» que debían cumprir as abadesas que, segundo os documentos conservados, adicaron os seus esforzos á fundación e á organización da vida comunitaria nos primeiros anos do mosteiro, para centrarse a partir dese momento na adquisición, explotación e defensa das propiedades, na administración dos coutos e terras que integran o dominio monástico e no cobro das cantidades situadas sobre rendas concedidas por Afonso XI e confirmadas polos seus sucesores.

Foi Sancha Eanes, primeira abadesa de Santa Clara por vontade da fundadora Violante de Aragón e nomeada por ela testamenteira en 1302, quen sacou adiante o proxecto. Como testamenteira velou polo cumprimento das últimas vontades da raíña para co mosteiro e como abadesa desempeñou un papel relevante no conflito co bispo de Ourense na consagración da igrexa e o cemiterio en 1294. A súa actuación tamén foi básica na adquisión do patrimonio monástico mediante a compra de propiedades nos arredores do mosteiro e nos actuais concellos de Allariz, Paderne de Allariz, Xunqueira de Ambía e Rairiz de Veiga ${ }^{35}$.

Superado con éxito o momento da fundación, a adquisición do patrimonio produciuse na maior parte dos casos a través de doazóns e mandas testamentarias nas que participaron en maior ou menor medida todas as abadesas.

A explotación das terras de labor realízase no mosteiro de Santa Clara mediante o outorgamento, confirmación, cambios nos bens e licenzas dos omnipresentes contratos forais, que supoñen unha elevada porcentaxe da documentación conservada. As concesións concéntranse sobre todo no século xv e unicamente María Fernández, Mor de Limia e Mor de Silván non outorgan ningún foro, posiblemente pola pouca documentación que dos períodos en que foron abadesas chegou ata a actualidade.

A defensa das propiedades, dereitos xurisdicionais e rendas do mosteiro centrou tamén boa parte da actividade despregada polas abadesas de Santa Clara. Na salvagarda dos bens inmobles tanto urbanos como rurais destacan as actuacións de tres abadesas: Margarida Gómez no século xiv e Sancha Salgada e María Méndez de Zarracós no XV. A primeira consegue que dona Leonor González, para evitar «pleitos e custas, danos e a escomoyon», entregue ao convento os bens que herdara do seu home, o escudeiro Men Rodríguez de Vilaseco, e o pago de dous mil marabedís «por pena e postura» en $1424^{36}$. Tamén co obxectivo de evitar preitos, a abadesa Sancha Salgada chega a un acordo en 1483 co escudeiro Xoán de Robreda para que renuncie ao casal que fora da monxa Leonor Fernández a cambio de percibir mentres viva oitenta marabedís da renda do casal, quedando os catro restantes para Santa Clara como recoñecemento de señorío ${ }^{37}$. Cando o acordo non é posible, óptase por interpoñer unha denuncia ante o xuíz ordinario de Allariz, como sucede na construción sen

35 AHN, Clero, Santa Clara de Allariz, 1429/5; 4900/1-1-1, f. 7r-v; e 1429/6.

36 AHPOu, Santa Clara de Allariz, Lib. 30/414r-415r.

37 AHPOu, Santa Clara de Allariz, Lib. 90/178. 
permiso dunha casa nunha propiedade do mosteiro, na Fontaíña ${ }^{38}$. O último instrumento utilizado para preservar as propiedades do mosteiro foron as pescudas e apeos que en 1496 ordenou María Méndez de Zarracós no couto de Nocelo da Pena e no lugar de Pazos ${ }^{39}$.

A defensa dos dereitos xurisdicionais do mosteiro ocupou boa parte das denuncias presentadas polas abadesas. En 1378 dona Leonor reclama as exencións de taxas no seu couto vulneradas polos oficiais do concello de Allariz e, en 1490, Sancha Salgada presenta unha queixa pola usurpación da xurisdición dese mesmo couto ${ }^{40}$.

No referido ás rendas reais, as primeiras reclamacións efectuadas por unha abadesa, da que non coñecemos o nome, prodúcense en 1336 polos impagos das rendas situadas en Viana e no Bolo, ás que seguirán as protestas sobre as do couto de Castrelo de Miño en 1417, que continuou Margarida Gómez, ao tempo que reclamaba tamén os pagos situados no celeiro de Vilanova dos Infantes en 1424. Nos últimos anos do século XV, en 1482, será Sancha Salgada a abadesa que proteste polo impago dos décimos dos portos en Baiona ${ }^{41}$.

Con frecuencia a importancia dalgúns asuntos levou ás abadesas a saír da clausura e acudir alí onde os xuíces escoiten as súas alegacións e resolvan os seus problemas (Rodríguez 1993: 100). Segundo a documentación, a primeira foi Mor de Limia, que en 1446 acode á aldea de Mourazos para recibir como vasalos aos moradores do couto. En 1450 Mor de Silván recibe en Ourense os bens que a monxa Esteveíña Nunes deixou ao convento. E, por último, Sancha Salgada, despois dunha primeira experiencia fóra do convento en 1474 cando aínda era monxa, volverá saír ata «las puertas de Vydal Ferrero, que son en la freguesya de Santo Esteboo» en 1490 para denunciar ante Nuno Soutelo, xuíz de Allariz, a Xoán Fernández por estar a facer, sen dereito nin permiso, casa nun pardiñeiro na rúa da Fontaíña, que era propiedade do convento, e tres anos despois, en 1493, desprazouse ata a aldea de Vilardevós para ordenar aos seus oficiais que non consintan a Francisco de Estúñiga nin a ningunha outra persoa perturbar a posesión do couto de Mourazos ao mosteiro de Santa Clara ${ }^{42}$.

O segundo lugar na xerarquía da comunidade monástica de Santa Clara ocúpano as vigairas, que actúan en representación da congregación en actos xurídicos realizados no mosteiro ou fóra del, auxiliando á abadesa ou substituíndoa

38 AHPOu, Santa Clara de Allariz, Lib. 4/553r.

39 Para Nocelo da Pena vide AHPOu, Santa Clara de Allariz, Lib. 14/232r-234r. Para Pazos, AHPOu, Santa Clara de Allariz, Lib. 42/4r-6r.

40 AHN, Clero, Santa Clara de Allariz, 1430/5. AHPOu, Santa Clara de Allariz, Lib. 29/42-43 e Lib. $31 / 17 \mathrm{rv}$

41 AHN, Clero, Santa Clara de Allariz, 1430/3. AHPOu, Santa Clara de Allariz, Lib. 47/163 e Lib. 47/160r; 216v-217r e 375.

42 AHPOu, Santa Clara de Allariz, Lib. 29/42-43. AHPOu, Santa Clara de Allariz, C. 6/62. AHPOu, Santa Clara de Allariz, Lib. 4/553r e Lib. 31/18. 
cando non está presente ${ }^{43}$. Entre 1288 e 1500 a documentación recolle tres vigairas: Berenguela López, vigaira de Constanza López entre 1361-1363; Beatriz Afonso, que aparece como vigaira de Leonor Álvarez de Robreda en 1454, e Tareixa García, que exerce baixo o mandato de María Méndez de Zarracós en 150044.

Tanto Beatriz Afonso como Tareixa García aparecen xunto á abadesa do convento no outorgamento dos dous foros nos que figuran, a primeira en 1454, primeiro ano como abadesa de Leonor Álvarez de Robreda, e a segunda en 1500, coa abadesa María Méndez de Zarracós. Coa cautela que impón que só haxa unha mención para cada unha, podemos supoñer que actuaban como auxiliares das abadesas na administración económica ${ }^{45}$.

Distinto é o caso de Berenguela López, que aparece por primeira vez como vigaira substituíndo á abadesa Constanza López nos últimos anos da súa vida, no outorgamento de dous documentos de carácter económico: outorgando unha licenza para aforar en 1361 á monxa dona Tereixa Téllez e aforando parte dun casal en Biduedo con licenza do convento en $1446^{46}$.

Calcular o número de monxas que profesaron no convento ao longo do período medieval é complicado porque depende directamente da cantidade de documentos conservados, que aumentan exponencialmente ao longo do século XV, e dos cambios na redacción da intitulación, na que nos dous primeiros séculos de vida do mosteiro se utilizan normalmente fórmulas xenéricas como «conuento do dito mosteiro», «ao conuento e frayras do dito mosteiro» ou «as frayras e monjas do dito mosteiro», que non identifican a ningunha monxa en particular ${ }^{47}$.

Será a partir do segundo cuarto do xv cando comecen a aparecer as primeiras mencións nas que se identifican polo seu nome unha parte das monxas que asisten ao cabido, como sucede nun foro de 1429 no que aparecen «Beatriz Afonso, e Moor Ferrandez, e Eynes Gomez, e Eynes Gonçalues, e Eynes de Ramoyn, e Tereyja Affonso, e Costança Gomez, e Lyonor de Reboreda, monjas do dito mosteiro, nós todas, e outra grande parte das donas e monjas do dito noso moesteiro que estamos juntadas dentro, ena igleia de Santa Maria a Grande, per canpãa tangida, segundo que avemos de vso e de custume de nos ajuntar pera o tal negoçio» ${ }^{48}$.

Sendo conscientes de que nin sequera no mellor dos casos podemos saber exactamente cantas monxas formaban parte da comunidade, en Allariz conta-

43 Na documentación de Santa Clara non aparece a figura da procuradora interna da comunidade (ou celareira), cuxa función, segundo o estudo de Rodríguez Núñez sobre as mendicantes femininas en Galicia, era encargarse da «percepción de rendas e pagos no mosteiro, o que implicaría o mantemento da contabilidade do mesmo» (Rodríguez 1993: 106).

44 AHPOu, Santa Clara de Allariz, Lib. 19/422. AHPOu, Santa Clara de Allariz, C. 6/45. AHPOU, Casa de Vilanova de Arroxo, Ca. 23942/01. AHPOu, Santa Clara de Allariz, Lib. 16/463r-464v.

45 AHPOU, Casa de Vilanova de Arroxo, Ca. 23942/01. AHPOu, Santa Clara de Allariz, Lib. $16 / 463 r-464 v$.

46 AHPOu, Santa Clara de Allariz, Lib. 19/422 e C. 6/45.

47 AHPOu, Santa Clara de Allariz, C. 6/50 e 52.

48 AHPOu, Santa Clara de Allariz, C. 6, n.․57. 
bilízanse un total de cincuenta e dúas monxas ao longo do período medieval, divididas cronoloxicamente da seguinte maneira: dúas entre 1288 e 1300, once durante o século XIV, vinte na primeira metade do S. XV e trinta e nove entre 1454 e 1500 . A finais da Idade Media, no ano 1499 catorce monxas asisten ás reunións capitulares, cifra que Rodríguez Núñez, no seu estudo sobre as mendicantes galegas, considera alta posto que o seu ingreso estaría posiblemente limitado pola capacidade económica do convento (Rodríguez 1993: 114).

Respecto á composición social, os estudos das comunidades de clarisas na Coroa de Castela e en Galicia destacan a súa aristocratización ao ser escollidas con frecuencia para a educación e forma de vida das mulleres pertencentes á nobreza, condición que se intensifica nas que desempeñan cargos directivos nos mosteiros ${ }^{49}$. O indicio que permite identificar ás nobres de forma máis segura é a utilización de dona ou don antepostos ao seu nome ou ao dalgún familiar directo; seguindo ese criterio e exceptuando as abadesas incluídas na táboa 1, en Allariz aparecen no século XIV seis nobres: Tareixa Rodríguez e Inés e María Rodríguez, viúva e fillas respectivamente de Rodrigo Méndez de Ambía; Inés Rodríguez, filla de Rodrigo Fernández de Limia e neta de Fernando Eanes Churrichao; Berenguela López, filla de Sancho López de Robreda e dona Aldonza Martiz, e Tareixa Téllez, filla de Rodrigo González Tello e dona Xoana.

No século seguinte, en 1439 destaca, pola riqueza dos ben achegados Constanza González de Laza, sobriña de Tareixa Eanes do Carballo, e en 1402 aparece a única monxa que procede a ciencia certa dunha familia burguesa, Esteviña Nunes, filla de Pedro Eanes do Portelo ${ }^{50}$. Coñecemos tamén o caso de María Rodríguez, que é nomeada por primeira vez como asistente ao cabido do 13 de abril de 1496 como criada da monxa Aldonza González e reaparece ao día seguinte convertida en monxa, conversión que podería facernos pensar nunha relación de parentesco ou familiaridade entre ambas ${ }^{51}$.

Se a información sobre as monxas provenientes de familias nobres ou burguesas é escasa, a referida ao resto da congregación tampouco é abundante. A esa escaseza hai que engadir a dificultade de interpretar o valor dos dous termos que con maior frecuencia se utilizan para denominar as integrantes da congregación: monxas e freiras. Durante o século XIV nas intitulacións destácase a abadesa do «convento do mosteiro», termo xenérico para referirse á comunidade monástica, pero dende principios do xv comeza a diferenciarse sistematicamente entre «o conuento e frayras do dito mosteiro $»^{52}$ ou entre «frayras e monjas do dito mosteiro» $»^{53}$, expresións

49 García Oro sustenta esa tese para o conxunto dos mosteiros de clarisas hispanos (García Oro 2006: 138) e Rodríguez Núñez destaca para Santa Clara de Allariz o peso das monxas nobres fronte á única burguesa, Esteviña Núnez, que aparece na documentación do mosteiro nos anos 1402-1433 (Rodríguez 1993 : 47-48). Vide tamén AHPOu, Santa Clara de Allariz, Lib. 66/51v; C. 6/51 e 62.

50 AHPOu, Santa Clara de Allariz, Lib. 24/1r-3r e C. 6/51.

51 AHPOu, Santa Clara de Allariz, Lib. 16/436v-437v e 460rv.

52 AHPOu, Santa Clara de Allariz, C. 6/52.

53 AHPOu, Santa Clara de Allariz, C. 6/55. 
que parecen diferenciar o convento formado polas monxas profesas, das freiras, leigas que terían a función de atender asuntos da comunidade fóra do mosteiro. Porén, a partir de 1437 utilizaranse expresións como «donas e convento do dito mosteyro», «donas e monjas do dito noso moesteiro» ou «todas frairas donas do dito mosteiro» ${ }^{54}$, nas que a hipotética diferenciación desaparece ou cambia de significado (Rodríguez 1993: 109).

Só cinco monxas, as frayras Tareixa Rodríguez, Dominga Estévez e Aldonza Estévez e as monjas Sancha Salgada e Constanza Pérez, actúan en representación do mosteiro durante a Idade Media.

As tres primeiras aparecen en dúas ocasións, na primeira dise que as «frayras do dito mosteiro de Santa Clara» Tareixa Rodríguez e Aldonza Estévez compareceron no claustro da igrexa de Santiago de Allariz xunto cun procurador do convento, Xoán de Santa Clara, para denunciar que os cobradores de diversos tributos na vila de Allariz non gardan os privilexios e exencións do convento e dos seus dependentes ${ }^{55}$. Na segunda, a súa tarefa foi denunciar o impago dos dous mil marabedís anuais que o convento tiña situados nas rendas do couto de Castrelo de Miño. Para iso preséntanse ante os xuíces reais en Ribadavia cun poder da abadesa Margarida Gómez e un escrito de «requerimento e de fronta» no que solicitan que se obrigue a pagar aos arrendadores das rendas sen que se esixa ningunha prenda aos couteiros ou a quen labre as herdades do couto ${ }^{56}$.

No caso das monxas Sancha Salgada e Constanza Pérez, as saídas do convento teñen como obxectivo a xestión de propiedades aforadas. Sancha Salgada actúa cun poder da abadesa e monxas de Santa Clara para aforar no seu nome herdades na aldea de Mourazos ${ }^{57}$. Pola súa parte, Constanza Pérez toma posesión en tres ocasións, entre o 16 de agosto e o 4 de setembro de 1487, dunha viña que finalmente presenta ante Vasco de Nanín, xuíz do couto de Santa Clara, para obter a completa posesión da viña ${ }^{58}$.

Entre os casos descritos aparecen algunhas diferenzas significativas que poderían estar relacionadas coa existencia dos dous grupos de monxas que describe Rodríguez Núñez no seu estudo sobre as mendicantes galegas: o das monxas pertencentes ao «grupo reitor do convento», no que estarían Sancha Salgada e Constanza Pérez, ambas as dúas capitulares, identificacadas como monja e resolvendo problemas relacionados coa xestión de bens aforados; e o das monxas externas, profesas adicadas á xestión de asuntos externos que non se axustan á definición de «serviciais ou conversas», con frecuencia iletradas, ao que poderían pertencer Tareixa Rodríguez, Dominga Estévez e Aldonza Estévez, denominadas freyras, e que partici-

54 AHPOu, Santa Clara de Allariz, C. 6/58 e 57. AHPOu, Santa Clara de Allariz, Lib. 18/497-498.

55 AHPOu, Santa Clara de Allariz, Lib. 47/157r.

56 AHPOu, Santa Clara de Allariz, Lib. 47/160r.

57 AHPOu, Santa Clara de Allariz, Lib. 73/113v-115r.

58 AHPOu, Santa Clara de Allariz, Lib. 5/24r e 24r-v. 
pan na resolución de problemas vinculados coa exención de tributos na vila de Allariz ou coas malas prácticas dos recadadores de rendas reais no couto de Mourazos.

Para Rodríguez Núñez existe unha clara diferenza na extracción social entre os dous grupos pero indica que, máis aló das funcións que cumpren no mosteiro, non existían diferenzas á hora da toma de decisións na comunidade. No caso de Allariz, a falta de documentación non permite comprobar cal foi a participación das tres freiras mencionadas nos asuntos da comunidade (Rodríguez 1993: 111-112).

Sabemos moi pouco da vida cotiá das monxas de Allariz porque os procesos de produción e conservación das fontes documentais do mosteiro preservaron sobre todo documentos relacionados coa administración dos seus bens e as transaccións económicas que dela se derivaron. O único documento que describe un dote é a confirmación que o conde Sancho de Ulloa fai en 1487 da doazón a Santa Clara que o seu mordomo, Afonso de Entrala, fixo das xeiras entregadas polos veciños de Mourazos ao casteleiro de Oímbra «con vna su hija que metiera frayra» ${ }^{59}$.

A documentación si conserva, en cambio, a memoria da protección outorgada ás monxas polo rei Sancho IV, que en 1286 outorga, no mesmo privilexio en que acouta o lugar sobre o que se está a construír o mosteiro, un permiso ás clarisas de Allariz para herdar e dispoñer do seu patrimonio persoal. Protexidas polas concesións de reis e papas, as clarisas puideron conservar, adquirir e administrar os bens que herdaban baixo certas condicións, proceder que quedou rexistrado nas transaccións económicas que realizaron elas mesmas durante a súa vida no mosteiro.

Para administrar os bens que conservan despois da súa entrada en clausura as monxas necesitan o permiso da abadesa e das monxas que integran o convento. Para evidenciar o acordo do mosteiro, os documentos que rexistran as disposicións ou transaccións realizadas utilizan fórmulas que insisten na concesión da licenza e na presenza física de quen autoriza o acto xurídico. Así, no aforamento outorgado por Beatriz e Violante Afonso en 1413 indícase que se fixo «con liçençia et outorgamento de dona Leonor Gonçalues, abadesa do dito moesteiro, que está presente e outorgante a esta carta e ao que se en ela contén» ${ }^{60}$.

Nalgúns casos abadesa e convento van máis aló da simple autorización ou permiso, como sucede en 1350 cando a monxa Berenguela López de Robreda arrenda por dous anos os seus bens en terras de Viana, O Bolo e Trives, indicando que o fai non só por outorgamento e licenza da abadesa Constanza López e do convento, senón tamén polo seu mandado, ou en 1376 cando Clara Afonso, recibida «liçençia e outoridade e con outorgamento de dona Lionor, abadesa do dito mosteiro, e do conuento do dito mosteiro», afora os bens que posúe arredor do río Arnoia por ela e polo mosteiro, e sinala, como receptores das rendas xeradas, a si mesma mentres viva e ao mosteiro despois da súa morte. Proceder menos incisivo pero probablemente máis

59 AHPOu, Santa Clara de Allariz, Lib. 31/13.

60 AHPOu, Marqués de Leis, C. 24/2. 
frecuente é o de incluír ao mosteiro na cláusula de retracto na que se indica que, se os foreiros quixesen vender, debía ser frontada a monxa que afora ou o mosteiro ${ }^{61}$.

As compravendas conservadas na documentación de Santa Clara, todas elas realizadas co previo consentimento da abadesa e convento, son un bo expoñente da capacidade das monxas allaricenses para dispoñer das súas propiedades. Así, en 1408 Margarida Gómez, futura abadesa de Santa Clara, merca a Aldonza Estévez, monxa de Santa Clara de Ribadeo, todo o que esta recibiu como herdo dos seus pais no bispado de Ourense por 300 marabedís, e encarga do pago a frei Fernando de Lugo $^{62}$. E, en 1482, Ines de Ramuín afirma que a abadesa e o convento lle outorgaron a licenza para vender todo o que herdou dos seus pais a don García Díaz de Cadórniga por vinte mil marabedís, «acatando mis enfermedades e grandes dolençias que en mi cuerpo tengo, e pera los remedios dellas» ${ }^{63}$.

A venda dunha herdade en Mazaira que no ano 1331 fixeron ao mosteiro de Montederramo as irmás e monxas Inés e María Rodríguez semella ser o último chanzo na superación do enfrontamento entre a súa familia e o mosteiro cisterciense. Enfrontamento do que nos informan tres documentos outorgados por dona Tareixa Rodríguez, nai de Inés e María e tamén monxa en Santa Clara. No primeiro dos cales, datado ca. 1303, doa a Santa María de Montederramo lugares en Santa Mariña de Asadur polos grandes danos que o seu irmán fixera ao mosteiro; no segundo, de 1319, fai unha nova doazón ao mosteiro «por emenda das malfeytorias e das roubas» que lle fixera o seu fillo Xil Nunes neses mesmos lugares; e, por último, en 1329, confirma a renuncia que ela e o seu marido fixeran sobre herdades en Costa de Asadur, renuncia que, polo que parece, nunca cumprira ${ }^{64}$. Os documentos de 1303 e 1319 foron outorgados ante notario no mosteiro de Santa Clara sen que conste a licenza da abadesa e do convento, comportamento sen ningún precedente coñecido entre as integrantes do convento e difícil de explicar a pesar da condición social da outorgante.

Exemplo da presión que o mosteiro chegou a exercer sobre as mulleres que se acollían á súa hospitalidade foi o acontecido con dona María López de Lemos, que no testamento que redactou en 1313 revoga a doazón que fixera a Santa Clara argumentando que a doazón non era «perfeyta nem acabada» e que a fixo estando presa no mosteiro contra a súa vontade, sen poder saír e levada ao mosteiro mediante engano; que a abadesa e donas lle foron «moyto engratas» e que non tiñan aínda a posesión nin o dereito dos bens previamente doados, razóns suficientes para unha revogación ao non ter ela ingresado no mosteiro, ás que engade que «o dereyto

61 AHPOu, Santa Clara de Allariz, Lib. 30/408v-409v. AHPOu, Santa Clara de Allariz, C. 6/46. AHPOu, Santa Clara de Allariz, Lib. 15/6.

62 «...os quaes ditos trezentos marabedis da dita moneda me por ela deu e pagou frey Fernando de S[...] de Lugo en dineiros feitos e en panores de prata, que os montou a meu prazer e os eu reçeby en façe do notario e testemoias desta carta», Arquivo do convento de Santa Clara de Allariz, n.․․ 17.

63 AHPOu, Santa Clara de Allariz, Protocolos, 3322.

64 ACO, Monacais, Montederramo, n.o 2193, 1767, 2001 e 2160. 
manda que, se home ou moller de orden algũa cousa der a aquel moesteyro hu está en orden et se despoys del seýr, que leue todo aquelo que lle deu», deixando no aire a dúbida sobre un posible ingreso no convento do que despois se arrepentiu ${ }^{65}$.

Que en 1380 as Cortes de Soria establezan que os mosteiros fosen considerados como herdeiros directos dos bens obtidos en calquera maneira polas monxas, sen necesidade de testamentos específicos, podería explicar que non se conservase na documentación de Santa Clara ningún testamento outorgado por monxas ou freiras (Rodríguez 1993: 175). Posiblemente tamén facilitou á institución reclamar os seus dereitos sobre o herdo das monxas, tal e como sucedeu coa entrega ao mosteiro que fixo Nuno González, párroco de Santiago de Allariz, dos bens da monxa defunta Esteveíña Nunes, filla de Pedro Eanes do Portelo, por entender que retelos era unha práctica abusiva contra a institución, herdeira da monxa nos bens usurpados ${ }^{66}$.

Fóra do convento pero traballando para el aparecen os mordomos, oficiais que participaban na administración do patrimonio e na recadación de rendas, desenvolvendo o seu traballo en lugares nos que as monxas posuían dereitos xurisdicionais ${ }^{67}$. A eles súmanse os procuradores, que se ocupan das reclamacións, demandas e preitos en defensa das propiedades, dos dereitos xurisdicionais e do pago de rendas que conforman o patrimonio monástico, labores que os obrigan a presentarse ante os xuíces ou realizar desprazamentos que poden ocupar varias xornadas para facer pescudas e apeos de bens. Documéntanse ao longo da Idade Media dezanove procuradores de Santa Clara, algúns dos cales exerceron simultaneamente o cargo de mordomo. Cítanse tamén entre os traballadores dependentes do mosteiro dous criados, dous acemeleiros da abadesa e catro carpinteiros, sen que saibamos deles nada máis que os seus nomes e oficios.

En conclusión, o mosteiro de Santa Clara de Allariz, fundado pola raíña Violante de Aragón na vila real de Allariz, agasallado polos seus sucesores no trono con substanciosas cantidades de diñeiro situadas sobre rendas reais e elixido pola nobreza da contorna como casa das súas fillas e retiro das matriarcas viúvas, revélase como un importante centro de poder feminino en terras do bispado de Ourense. Lamentablemente unha documentación moi deturpada polos problemas de conservación dificulta seguir ás clarisas de Allariz na súa vida dentro do mosteiro, da que unicamente se conservan algúns flashes nos que aparece unha nai compartindo vida coas súas fillas tamén monxas, o cabido autorizando a venda dos bens doutra monxa para adquirir os remedios que alivien a súa enfermidade ou abadesas e freiras saíndo da clausura para defender os intereses da comunidade.

65 Lorenzo 2020: 955-963, doc. 774.

66 AHPOu, Santa Clara de Allariz, C. 6/62.

67 Segundo Olga Gallego, os mordomos completaban esas dúas funcións coa comercialización do que a comunidade non consumía, actividade que non quedou plasmada na documentación medieval do mosteiro (Gallego 1886a: 58). 


\section{REFERENCIAS BIBLIOGRÁFICAS}

- Domínguez SáncheZ, Santiago (2009): Documentos de Nicolás IV (1288-1292) referentes a España, León, Universidad.

- DuRany Castrillo, Mercedes (2009): «El convento de Santa Clara de Allariz (1282-1312)», en Raquel Casal/José Miguel Andrade/Roberto J. López (eds.), Galicia monástica. Estudos en lembranza da profesora María José Portela Silva, Santiago de Compostela, Universidade, 131-151.

- Gallego Domínguez, Olga (1986a): «Dominio y bienes de Santa Clara», en Santa Clara de Allariz. Séptimo Centenario de la Fundación. Boletín Auriense, Anexo 5, Ourense, 43-62.

- Gallego Domínguez, Olga (1986b): «El coto de Santa Clara de Allariz», en Santa Clara de Allariz. Séptimo Centenario de la Fundación. Boletín Auriense, Anexo 5, Ourense, 139-143.

- García BarRiuso, Patrocinio (1990): «Documentación sobre la fundación, privilegios y derechos históricos del Monasterio de Santa Clara de Allariz», en J. P. Paz (coord.): Santa Clara de Allariz: historia y vida de un monasterio, Ourense, Servizo de Publicacións da Deputación de Ourense, 11-107.

- García GonzáLEZ, Miguel Ángel (1990): «El arte en el monasterio de Santa Clara de Allariz», en J. P. Paz (coord.): Santa Clara de Allariz: historia y vida de un monasterio, Ourense, Servizo de Publicacións da Deputación de Ourense, 229-256.

- García Oro, José (1999): «La primitiva instalación de las clarisas en Galicia», en J. P. Paz (coord.): Santa Clara de Allariz: historia y vida de un monasterio, Ourense, Servizo de Publicacións da Deputación de Ourense, 109-145.

- GARCía ORo, José (2006): Los franciscanos en España: historia de un itinerario religioso, Santiago de Compostela, El Eco Franciscano.

- Garcimartín Muñoz, N./Sergio Santos Otero (2011-2012): «Documentación del archivo del Convento de Santa Clara de Allariz», Boletín Auriense, 41-42, 517-546.

- GonzÁLEZ Borrajo, Maa del Pilar (1986): «Evolución histórica del Monasteiro de Santa Clara de Allariz», en Santa Clara de Allariz. Séptimo Centenario de la Fundación. Boletín Auriense, Anexo 5, Ourense, 87-93.

- Katz, Melisa R. (2015): «A Convent for La Sabia. Violante of Aragón and the Clarisas of Allariz», en J. D'Emilio (ed.), Culture and society in medieval Galicia: a cultural crossroads at the edge of Europe, Leiden, Brill, 812-836.

- Limia Gardón, Francisco Xosé (1990): «El Convento de Santa Clara de Allariz entre los siglos XV al XVIII», en J. P. Paz (coord.): Santa Clara de Allariz: historia y vida de un monasterio, Ourense, Servizo de Publicacións da Deputación de Ourense, 147-199. 
- López, Atanasio (1915): La Provincia de España de los Frailes Menores. Apuntes histórico-críticos sobre los orígenes de la Orden Franciscana en España, Santiago, El Eco Franciscano.

- LóPEZ, Atanasio (1927): «Apuntes históricos sobre el convento de Santa Clara de Allariz (Siglos XIII y XIV», BCMO, VIII:172, 173, 174, 8-18, 25-32, 49-53.

- LoRENZO, Ramón (2020): Colección documental do mosteiro de Montederramo, Santiago de Compostela, Consello da Cultura Galega.

- Mapa de parroquias de Galicia 1:200.000 (2009): A parroquia en Galicia. Apéndice estatístico e cartográfico, Xunta de Galicia, SITGA.

- Nieto Soria, José Manuel (1990): «Franciscanos y franciscanismo en la política y en la corte de la Castilla Trastámara (136-1475)», Anuario de Estudios Medievales, 20, 109-131.

- PÉREZ Rodríguez, Francisco Javier (2018) «Los mendicantes en el reino de Galicia: instalación, problemas y adaptación (siglos XIII-XIV)», en David Chao Castro/ Isabel González/Fernando López Alsina (coords.), Franciscanos en la Edad Media. Memoria, cultura y promoción artística, Edizioni dell'Orso, 97-113.

- Reglero de la Fuente, Carlos Manuel (2021): Monasterios y monacato en la España medieval, Madrid, Marcial Pons.

- Ríos, A. de los (1973): Historia social, política y religiosa de los judíos en España y Portugal, Madrid, Aguilar.

- RodríGuez MuÑIz, Clara Cristela (1993): Los conventos femeninos en Galicia. El papel de la mujer en la sociedad medieval, Lugo, Deputación Provincial.

- SÁnchez Ferro, Pablo/Ma Ascensión Enjo Babío (2011): «Achega ao estudo da “desmembración” do couto do Convento de Santa Clara de Allariz», Boletín Auriense, 41-42, 765-788.

- SBARALEA, Giovanni (1768): Bullarium franciscanum, Roma, Sacrae Congregationis de Propaganda Fide. 
